\title{
PENGARUH JENIS STEK TERHADAP KEBERHASILAN PEMBIBITAN BAMBU HITAM (Gigantochloa atroviolaceae Widjaja)
}

\author{
THE EFFECT OF CUTTING TYPES ON THE SUCCESS OF BLACK BAMBOO SEEDS \\ (Gigantochloa atroviolaceae Widjaja)
}

\author{
Aditya Hani \\ Balai Penelitian dan Pengembangan Teknologi Agroforestry \\ Jalan Ciamis-Banjar Km. 4 P.O. Box 5. Telp. 0265771352 \\ Emai: adityahani@gmail.com \\ Diterima: 23 Nopember 2020, Direvisi: 30 Nopember 2020, Disetujui: 11 Desember 2020
}

\begin{abstract}
ABSTRAK
Bibit bambu hitam melalui perbanyakan vegetatif masih perlu dikembangkan agar diperoleh teknik perbanyakan yang tepat. Uji coba pembuatan bibit bambu hitam asal stek cabang menghasilkan keberhasilan stek yang masih rendah. Penelitian ini bertujuan untuk mengetahui jenis bahan stek batang bambu hitam. Penelitian ini menggunakan metode rancangan acak lengkap (RAL) dengan perlakuan jenis stek yaitu stek asal batang bagian bonggol (sisa tebangan), stek batang 1 ruas, stek batang 2 ruas, stek batang 3 ruas. Parameter yang diamati yaitu: tinggi tunas, diameter tunas, jumlah tunas dan panjang akar. Hasil penelitian menunjukan bahwa perlakuan stek batang asal bonggol bambu menghasilkan pertumbuhan tunas terbaik pada semua parameter pertumbuhan.
\end{abstract}

Kata kunci: Akar stek, bambu hitam, stek batang

\begin{abstract}
Black bamboo seedlings through vegetative propagation still need to be developed in order to obtain the right propagation technique. Trials of making black bamboo seedlings from branch cuttings resulted in a low success rate. This study aims to determine the type of black bamboo stem cutting material. This study used a completely randomized design method (CRD) with the treatment of cuttings, namely: stem cuttings from the weevil (remaining cut), 1 -segment stem cuttings, 2segment stem cuttings, 3-segment stem cuttings. The parameters observed were shoot height, diameter, number of shoot and root length. The result show that the treatment of weevil stem cuttings produced the best shoot growth in all growth parameters.
\end{abstract}

Key words: Black bamboo, root cuttings, stem cuttings 


\section{PENDAHULUAN}

Bambu hitam merupakan salah satu jenis bambu yang mempunyai banyak kegunaan. Masyarakat di Jawa Barat memanfaatkan bambu hitam untuk pembuatan alat musik, kerajinan dan furniture (Nurmala, 2018). Bambu hitam memiliki kelas awet 2 (tahan) terhadap serangan rayap tanah sehingga cukup baik untuk digunakan sebagai bahan bangunan. Kualitas bambu juga dipengaruhi ketinggian tempat lokasi penanaman. Bambu hitam yang ditanam di daerah dataran rendah mengandung pati yang lebih tinggi (Nafitri \& Lukmandaru, 2013). Bambu hitam juga dapat digunakan sebagai bahan baku pembuatan asap cair karena mengandung senyawa asam asetat, metanol dan total fenol yang cukup tinggi (Komarayati \& Wibowo, 2015). Bambu hitam seperti pada umumnya jenis bambu sangat baik untuk konservasi tanah dan air karena memiliki perakaran serabut yang tersebar luas, seresah yang tebal dan tajuk dan kanopi yang rapat sehingga mengurangi limpasan permukaan (Mentari, Mulyaningsih, \& Aryanti, 2018).

Trimanto, Annisa, \& Hanasari, (2020) menyatakan bahwa informasi mengenai teknik pembibitan secara vegetatif bambu yang masuk genus gigantochloa salah satunya bambu hitam masih sangat terbatas. Uji coba pembuatan bibit bambu hitam asal stek cabang menghasilkan pertumbuhan terbaik diperoleh dari stek cabang dengan 4 ruas namun dengan tingkat keberhasilan stek yang masih rendah yaitu 33,33\% (Irvantia, Indriyanto, \& Riniarti, 2014). Hal ini menunjukan bahwa masih perlunya penelitian mengenai teknik pembibitan bambu genus gigantochloa yang tepat sehingga mampu meningkatkan keberhasilan pembuatan bibit. Faktor yang mempengaruhi keberhasilan stek bambu adalah bahan stek, media tumbuh dan faktor lingkungan (Saefudin \& Roswati,
2010). Penelitian ini bertujuan untuk mengetahui jenis bahan stek batang bambu hitam yang menghasilkan keberhasilan stek batang bambu terbaik.

\section{BAHAN DAN METODE Bahan dan Alat}

Bahan yang digunakan dalam penelitian ini adalah rumpun bambu hitam (Gigantochloa atroviolaceae Widjaja) sebagai sumber stek, sekam padi, tanah, plastik. Sedangkan alat yang digunakan adalah: gergaji, parang, cangkul, kawat, gunting dan ember.

\section{Metode}

Penelitian ini menggunakan metode rancangan acak lengkap (RAL) dengan perlakuan jenis stek yaitu: stek asal batang bagian bonggol (sisa tebangan), stek batang 1 ruas, stek batang 2 ruas, stek batang 3 ruas. Parameter yang diamati yaitu tinggi tunas, diameter tunas, jumlah tunas dan panjang akar (Setiawati, Soleha, \& Nurzaman, 2018). Penelitian ini dilakukan dengan tahapan: 1). Memilih lokasi persemaian yang mempunyai kelembaban tinggi, tanah subur serta ketersediaan air yang cukup, 2) Penyiapan media perakaran stek dengan cara mencampurkan antara tanah dan sekam padi perbandingan 1: 1., 3). Pembuatan bedengan dengan dengan cara menggali tanah kedalaman $15 \mathrm{~cm}$ kemudian bagian bawah diberi alas plastik yang sudah diberi lubang sehingga air tidak mudah hilang ke dalam tanah, 4). Media yang sudah disiapkan selanjutnya dimasukan ke dalam tanah yang sudah digali. Setelah tempat persemaian disiapkan selanjutnya menyiapkan bahan stek bambu dengan cara sebagai berikut: 1). Stek asal bonggol diperoleh dengan cara membongkar bonggol bambu hitam sisa tebangan, 2). Memotong batang sesuai perlakuan, pilih batang yang terlihat mempunyai calon tunas pada bagian buku, 3). Menanam 
potongan batang ke dalam bedengan dengan posisi mendatar, 4). Menimbun dengan campuran media tanah dan sekam yang sudah dipersiapkan. 5). Siram hingga tanah jenuh, 6). Tutup bedengan dengan membuat sungkup plasitik sehingga tidak ada udara yang keluar sehingga kelembaban terjaga, 7). Penyiraman dilakukan apabila sungkup terlihat tidak basah.

\section{Analisa Data}

Data hasil penelitian selanjutnya dianalisis menggunakan analisis keragaman (ANOVA). Apabila terjadi perbedaan yang nyata maka dilanjutkan dengan uji lanjut jarak berganda Duncan (DMRT), sehingga dapat diketahui perlakuan yang terbaik. Analisis data dibantu menggunakan Program SPSS Versi 26.

\section{HASIL DAN PEMBAHASAN}

Hasil analisis keragaman pengukuran pertumbuhan tunas bambu setelah 4 bulan di persemaian disajikan pada lampiran tulisan ini. Hasil analisi keragaman menunjukkan bahwa perlakuan jenis stek batang bambu menghasilkan respon yang berpengaruh nyata antar perlakuan pada seluruh parameter. Untuk mengetahui perlakuan yang terbaik maka dilakukan uji lanjut jarak berganda Duncan seperti disajikan pada Tabel 1.

Tabel 1.

Hasil uji lanjut Duncan pengaruh jenis stek terhadap pertumbuhan tunas (Table 1. The results of Duncan's continued test of the effect of cuttings on shoot growth)

\begin{tabular}{|c|c|c|c|c|}
\hline Perlakuan/Treatment & $\begin{array}{l}\text { Tinggi Tunas } \\
\text { /Height of } \\
\text { Shoot }(\mathrm{cm})\end{array}$ & $\begin{array}{l}\text { Diameter } \\
\text { Tunas/ } \\
\text { Diameter of } \\
\text { Shoot }\end{array}$ & $\sum_{\text {tunas/Shoot }}$ & $\begin{array}{l}\text { Panjang } \\
\text { akar/Lenght of } \\
\text { root }\end{array}$ \\
\hline Batang Bonggol & $187,14 \mathrm{a}$ & $1,30 \mathrm{a}$ & $7,86 \mathrm{a}$ & $19,57 \mathrm{a}$ \\
\hline 1 ruas & $57,56 \mathrm{~b}$ & $1,25 \mathrm{a}$ & $2,94 \mathrm{~b}$ & $5,68 \mathrm{~b}$ \\
\hline 2 ruas & $56,79 \mathrm{~b}$ & $0,64 \mathrm{~b}$ & $2,87 \mathrm{~b}$ & $8,75 \mathrm{~b}$ \\
\hline 3 ruas & $43,56 \mathrm{~b}$ & $0,57 \mathrm{~b}$ & $2,48 \mathrm{~b}$ & $5,94 \mathrm{~b}$ \\
\hline
\end{tabular}

\section{Tinggi tunas}

Tabel 1 menunjukan bahwa perlakuan stek batang bonggol menghasilkan pertumbuhan tinggi tunas terbaik $(187,14 \mathrm{~cm})$. Stek batang asal bonggol bambu mempunyai cadangan makanan dan air yang lebih besar yang ada di dalam batang yang lebih besar dibandingkan perlakuan yang lain. Air berfungsi untuk meningkatkan plastisitas dinding sel yang selanjutnya akan terjadi pemanjangan sel (Advinda, Fifendy, Anhar, Leilani, \& A.L, 2018). Keberadaan tunas yang merupakan tempat konsentrasi hormon auksin secara alami yang selanjutnya akan mempengaruhi pertumbuhan akar (Cahyadi,
Iskandar, \& Ardian, 2017), sehingga akan mempengaruhi keberhasilan stek.

\section{Diameter tunas}

Diameter tunas tertinggi ditunjukan pada tunas asal stek batang bonggol. Diameter merupkan hasil dari proses metabolisme dalam tanaman. Salah satu bahan yang diperlukan untuk proses metabolisme adalah unsur hara makro salah satunya yaitu nitrogen. Danu, Siregar, Wibowo, \& Subiakto, (2010) menyatakan bahwa kandungan unsur hara nitrogen terbesar ditemukan pada bagian batang yang berumur lebih tua, sehingga batang bonggol yang memiliki umur lebih 
tua dibandingkan batang atas memiliki kandungan nitrogen lebih besar yang akan menghasilkan hasil metabolisme lebih besar salah satunya dalam bentuk ukuran diameter.

\section{Jumlah tunas}

Jumlah tunas tertinggi ditemukan pada stek asal batang bonggol. Selain karena faktor ketersediaan unsur hara yang lebih tinggi pada bagian batang bonggol, jumlah tunas dapat disebabkan karena adanya akumulasi hormon auksin secara alami pada bagian bonggol. Utami et al. (2020) menyatakan bahwa hormon auksin diproduksi tanaman pada bagian pucuk (apikal) kemudian ditranslokasikan ke seluruh bagian tanaman dan terkonsentrasi pada bagian pangkal dan tengah batang, sehingga jumlah tunas akan lebih banyak muncul pada stek asal batang bagian pangkal (bonggol).

\section{Panjang akar}

Hal ini disebabkan pada stek yang berasal dari batang bonggol sudah memiliki perakaran yang sudah berkembang dengan baik. Perakaran menentukan keberhasilan stek untuk dapat terus tumbuh berkembang. Akar berfungsi untuk menyerap unsur hara dan air yang dibutuhkan untuk metabolisem stek. Pada saat tunas sudah mulai muncul namun perakaran belum ada maka dapat mengakibatkan kehilangan air yang cukup besar akibat transpirasi, keberadaan akar juga berfungsi untuk mensuplai makanan bagi stek (Prasetyawati, Wibowo, \& Budi, 2018). Apabila suplai makanan yang berasal dari akar mencukupi maka pertumbuhan organ-organ pertumbuhan yang lain akan lebih baik. Hal ini ditunjukan dari parameter tinggi tunas, diameter dan jumlah tunas. Kemampuan berakar dari setiap perlakuan disajikan pada Tabel 2.
Tabel 2.

Kemampuan berakar stek batang bambu hitam

Table 2.

Root ability of black bamboo stem cuttings

\begin{tabular}{lr}
$\begin{array}{c}\text { Perlakuan } \\
\text { (Treatment) }\end{array}$ & $\begin{array}{c}\text { Persentase berakar } \\
\text { (Percentage is rooted }) \\
(\%)\end{array}$ \\
\hline Batang & \\
Bonggol & 100 \\
1 ruas & 77,78 \\
2 ruas & 97,5 \\
3 ruas & 71,43 \\
\hline
\end{tabular}

Stek bambu pada umumnya didahului oleh munculnya tunas daun, setelah beberapa waktu lamanya baru mulai muncul akar. Kondisi ini menggambarkan bahwa pembentukan akar memerlukan suatu senyawa tumbuh yang mendukung untuk terjadinya pembentukan primordia akar (Winten, Putra, \& Gunamanta, 2017). Apabila akar tidak berhasil terbentuk pada umumnya tunas daun yang muncul akan mengering dan mati. Belum munculnya akar bisa jadi waktu pengamatan selama 4 bulan masih belum mencukupi. Hal ini ditandai dengan masih segarnya tunas daun pada bagian stek yang belum muncul akar. Proses perakaran dipengerauhi oleh beberapa faktor antara lain yaitu impermeabilitas kulit batang terhadap air (Hernosa \& Siregar, 2020), sehingga memerlukan waktu yang berbeda hingga kulit batang menjadi impermeabel sampai munculnya tunas akar.

Stek batang asal bonggol menghasilkan pertumbuhan stek terbaik. Di sisi lain stek batang asal bonggol memiliki kelemahan yaitu sulit mencari bonggol batang bambu hitam, memerlukan waktu dan biaya untuk membongkar bonggol, serta jumlah bibit yang dihasilkan hanya 1 individu dari batang bonggo tersebut. Penggunaan stek batang dapat dikembang- 
kan karena mempunyai kelebihan dimana dari 1 (satu) batang bambu dapat dipotong menjadi beberapa bahan stek. Ukuran keberhasilan stek apabila stek sudah muncul tunas sekaligus muncul akar yang sudah berkembang dengan baik. Berdasarkan hasil penelitian di atas stek batang bambu hitam dengan 2 ruas dapat digunakan sebagai bahan pembuatan stek batang bambu karena lebih efesien dengan persentase berakar yang lebih tinggi.

\section{KESIMPULAN}

Perlakuan stek batang bonggol menghasilkan pertumbuhan tunas terbaik yang ditunjukan dari persentase berakar, tinggi tunas, diameter tunas, jumlah tunas dan panjang akar. 


\section{DAFTAR PUSTAKA}

Advinda, L., Fifendy, M., Anhar, A., Leilani, I., \& A.L, S. 2018. Pertumbuhan stek horizontal batang jarak pagar (Jatropha curcas L.) yang diintroduksi dengan psedomonan fluoresen. EKSAKTA, 19(1), 68-75.

Cahyadi, O., Iskandar, A. M., \& Ardian, H. 2017. Pemberian rootone $F$ terhadap pertumbuhan stek batang puri (Mitragyna speciosa Korth). Jurnal Hutan Lestari, 5(2), 191-199.

Danu, Siregar, I. Z., Wibowo, C., \& Subiakto, A. 2010. pengaruh umur sumber bahan stek terhadap keberhasilan stek pucuk meranti tembaga (Shorea leprosula MIQ.). Jurnal Hutan Tanaman, 7(3), 1-14.

Hernosa, S. P., \& Siregar, L. A. M. 2020. Pengaruh asam indol butirat (IBA) pada pertumbuhan setek tanaman buah naga (Hylocereus costaricensis). Jurnal Pertanian Tropik, 7(1), 98108.

Irvantia, W., Indriyanto, \& Riniarti, M. 2014. Pengaruh jumlah ruas cabang terhadap pertumbuhan setek bambu hitam (Gigantochloa atroviolacea). Jurnal Sylva Lestari, 2(1), 58-66.

Komarayati, S., \& Wibowo, S. 2015. Karakteristik asap cair dari tiga jenis bambu. JURNAL Penelitian Hasil Hutan, 33(2), 167-174.

Mentari, M., Mulyaningsih, T., \& Aryanti, E. 2018. Identifikasi bambu di sub Daerah Aliran Sungai Lombok Timur dan alternatif manfaat untuk konservasi sempadan sungai. Jurnal Penelitian Pengelolaan Daerah Aliran Sungai, 2(2), 111-122.

Nafitri, M., \& Lukmandaru, G. 2013. Sifat kimia bambu hitam (Gigantochloa sp) pada perbedaan arah aksial dan ketinggian tempat tumbuh. In Prosiding Seminar Nasional Masyaraakt Peneliti Kayu Indonesia $X V I$ (p. 353).
Nurmala, M. 2018. Inovasi alat musik konvensional berbahan dasar bambu oleh Indonesia Bamboo Community. Dewaruci, 13(1), 1-10.

Prasetyawati, Y. E., Wibowo, C., \& Budi, S. W. 2018. Pengaruh keberadaan akar adventif dan media tanam terhadap pertumbuhan stek cabang bambu betung (Dendrocalamus asper Schult Backer). Jurnal SIlvikultur Tropika, 9(2), 109-115.

Saefudin, \& Roswati, T. 2010. Pemilihan bahan vegetatif untuk penyediaan bibit bambu hitam (Gigantochola atroviolacea Widjaja). Tekno Hutan Tanaman, 3(1), 23-28.

Setiawati, T., Soleha, N., \& Nurzaman, M. 2018. Respon pertumbuhan stek cabang bambu ampel kuning (Bambusa vulgaris Schard.Ex Wendl.var. Striata) dengan pemberian zat pengatur tumbuh NAA (Naphthalein Acetic Acid) dan Rootone F. Jurnal Pro-Life, 5(3), 611-625.

Trimanto, Annisa, D. W., \& Hanasari, D. 2020. Karaktarestik morfologi, perbanyakan vegetatif dan potensi bambu (Gigantochola dan Schizostahyum) sebagai tanaman untuk konservasi tanah dan air. Jurnal Pemuliaan Tanaman Hutan, 14(1), 43-53.

Utami, N., Himawati, S., Handayani, D. P., Surachman, M., Tanjung, A., \& Royani, J. I. 2020. Keberhasilan stek tanaman lamtoro varietas tarramba (Leucaena leucocephala cv. Tarramba) karena pengaruh umur fisiologis dan zat pangatur tumbuh. Pastura, 10(1), 42-45.

Winten, K. T. I., Putra, A. A. G., \& Gunamanta, P. G. 2017. Pengaruh panjang dan lingkar stek terhadap pertumbuhan bibit tanaman buah naga. Ganec Swara, 11(2), 39-44. 


\section{Lampiran}

Tabel 3.

Hasil analisis varian perlakuan perbedaan stek batang bambu hitam

(Table 3. The results of the analysis of variants in the treatment of differences in black bamboo cuttings)

\begin{tabular}{|c|c|c|c|c|c|}
\hline $\begin{array}{l}\text { Sumber } \\
\text { Variasi }\end{array}$ & $\sum_{\substack{\text { Kuadrat } / \sum \text { Squa } \\
\text { res }}}$ & $\begin{array}{c}\text { Derajat } \\
\text { bebas/Degr } \\
\text { ee of } \\
\text { fredom }\end{array}$ & $\begin{array}{c}\text { Kuadrat } \\
\text { Tengah/Me } \\
\text { an Square }\end{array}$ & $\begin{array}{c}\mathrm{F} \\
\text { hitung/Calculati } \\
\text { on }\end{array}$ & $\begin{array}{l}\text { Signifikan } \\
\text { si }\end{array}$ \\
\hline $\begin{array}{l}\text { Tinggi } \\
\text { tunas/Height } \\
\text { of shoot }\end{array}$ & 6800069.94 & 4 & 1700117,5 & 141,41 & $0,000 *$ \\
\hline $\begin{array}{l}\text { Diameter } \\
\text { tunas/Diamet } \\
\text { er of shoot }\end{array}$ & 70,009 & 4 & 17,50 & 115,21 & $0,000 *$ \\
\hline$\sum_{\text {tunas/Shoot }}$ & 1366,90 & 4 & 341,55 & 38,03 & $0,000 *$ \\
\hline $\begin{array}{l}\text { Panjang } \\
\text { akar/Lenght } \\
\text { of root }\end{array}$ & 88697,85 & 4 & 2174,46 & 37,11 & $0,000 *$ \\
\hline
\end{tabular}

